\title{
Interactions of Bio-macromolecules During Processing of Instant Asian Noodles: A Review
}

\author{
PRATIKSHA SHRESTHA ${ }^{* 1}$, KRISHNA PRASAD RAI ${ }^{2}$ and ANIL KUMAR ANAL ${ }^{1}$ \\ ${ }^{1}$ Food Engineering and Bio Process Technology (FEBT), Asian Institute of Technology, Pathumthani 12120, Thailand \\ ${ }^{2}$ Department of Food Technology and Quality Control, Babarmahal, Kathmandu, Nepal
}

The review focuses on how the protein, fats, carbohydrates and water interact and form the complexes during different stages of processing of instant noodles. Moisture is needed for dough formation and chemical interactions therein. Appropriate moisture content is required for proper gelatinization of noodle strand during steaming and eventually moisture is evaporated off by drying and frying to increase its shelf life. Frying oil may undergo degradation process invited by high frying time and temperature, high moisture in oil and polyvalent metals. Various intermediate products like dimers and polymers accelerate the oil degradation finally changing the physiochemical properties of oil rendering it unacceptable for processing. Gliadin and glutenin gives noodle its viscoelastic character. The polymeric glutenin network develops throughout the process of mixing, resting and subsequent stages of sheeting. Protein content and amylose content in noodle are inversely proportional to the oil uptake ratio. Another possibility is the non-enzymatic browning reaction during frying of instant noodles.

Keywords: Instant noodles, Biochemical reaction, Nutritional aspects, Processing, Quality

\section{Introduction}

Instant noodles are ready to serve with easy preparation. There are two main types of instant noodles: a) steamed and deep-fried and b) steamed and air-dried pre-cooked instant noodles need only 3-4 min of boiling or rehydration with boiling water to prepare for serving. The frying process removes the water from the noodle strands, resulting in a porous structure that rehydrates quickly when hot water is added.

Asian Noodles can be broadly divided into two classes a) salted noodles and b) yellow alkaline noodles. The most apparent difference between the two types is the addition of alkali (sodium and potassium carbonate). The yellow color of the noodle is due to the chemical reaction of flavones under alkaline condition. Asian noodles are generally made from durum wheat flour (Cuesta, et al., 1993) as it gives superior color and better texture (Fu, 2006). Durum wheat is hard wheat containing high protein. According to (CAC, 2016), durum wheat flour shall not contain less than $11 \%$ protein. The gluten protein the elasticity character. Increasing the protein content of flour also contributes to firmness (Karim, 1990).
There is no any approved international standard method for preparation of instant Asian noodles. However, there are basic guidelines as shown in Figure 1, which needs to be followed for maintaining quality characteristics of Asian Noodles.

Preparation of salt solution (Solution of Sodium carbonate, Phosphate salts and gums)

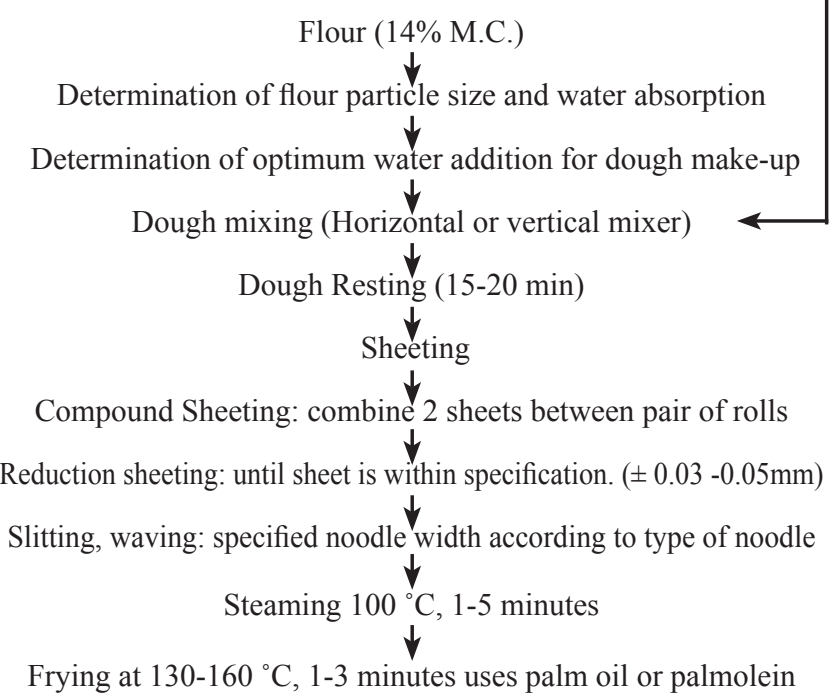

Figure 1. Guidelines for Instant Asian Noodles making process (Ross, 2005)

\footnotetext{
*Corresponding author, E-mail: pratiksha.shrestha2001@gmail.com
} 
Noodles represent a complex system in which multiple components interact to achieve final characteristic product. The interactions or combined effects of water, starch protein and lipid under various conditions are the components of major concern in the processing and product quality of Asian noodles. Dough and noodle quality is affected by wheat proteins (Gary, 2013), starch (Noda et al., 2001), lipids (Lu, et al., 2009), and enzymes (Fu, 2008).

Protein, glycans and lipids are the major bio-macromolecules involved in noodle processing. Bio-macromolecules are the biopolymers formed by joining together small building blocks (bio-molecular monomers) in the cells (Tsai, 2007). There are mainly 3 true macromolecules; carbohydrate, protein and nucleic acid. Lipid is not truly a macromolecule. Monomer constituents of bio-macromolecules are monosaccharides (for glycans), amino acid (for protein), and glycerol and fatty acid (for lipid). For bio-macromolecules, there is usually a tetrahedral arrangement of bonds around single-bonded carbon atoms and phosphorus atoms. Organic molecules, including bio-macromolecules, are held together with covalent bonds. Their 3D structures are characterized by bond lengths, bond angles and rotations of groups of atoms about the bonds Covalent bonds are the major source of energy for cells when broken. Computer graphics provides the most comprehensive tool for depicting 3 dimensional structures of biomolecules.

\section{Competition of protein and starch for water during mixing}

During dough mixing, proteins, pentosans and starch compete for the limited amount of water available. Since the starch comprises at least $70 \%$ of the flour, it will absorb a substantial amount of the water. Starch which has been damaged in the milling process has an even greater affinity for water absorbing up to three times as much water as undamaged starch (Kruger, 1996).

In Asian noodles, alkali is added in water to increase water absorption and decreases the mixing requirement of wheat flour dough. Larger increase in water absorption is with sodium hydroxide than with either sodium or potassium carbonates (Moss, 1986). Alkali addition also affects the gelatinization properties of starch. For example; sodium hydroxide can gelatinize starch at room temperature (Maher, 1983). Changes in dough properties under alkaline condition have been attributed to oxidation of sulfhydryldisulfide exchange and oxidation of globulin fraction to form high molecular weight proteins (Terada, 1978).

Alkali can be powder which is also called "soda ash"or liquid form that is termed as "lye water". In Japan, mixture of sodium and potassium carbonate (kansui) are more common. Optimal firmness for instant noodles is observed with either $0.215 \%$ kansui or $2.0 \% \mathrm{NaCl}$. However, the addition of kansui reduced noodle nutritional quality, and high levels of both table $(2.03 .0 \%)$ and alkaline $(1.001 .5 \%)$ salt increased cooking losses (Rombouts, et al., 2014). Powders of black soda are dissolved in water to prepare the solution. The chemical ingredients are dissolved in water (soft water) and stored in storage tank. The $\mathrm{pH}$ of the mixing water is maintained at $7.2-7.5$ at $20^{\circ} \mathrm{C}$ during storage. Likewise, salt solution is prepared in separate tank and fed into the mixing batch at continuous rate.

In noodle making, incorporation of water with added ingredients is carried out such that actual dough development is minimized. Furthermore, absorption of water is only 29 - 30 percent. The incorporation of water is mainly done to have enough water to hydrate the flour. Less moisture content of dough means that there will be less water to eliminate during subsequent steps of drying and frying. The water absorption is dependent on the type of flour. Water temperature affects mixing time and noodle quality. If water temperature is too low $\left(<18{ }^{\circ} \mathrm{C}\right)$, it slows down flour hydration speed and gluten development and requires a longer mixing time. If water temperature is too high $(>30$ ${ }^{\circ} \mathrm{C}$ ), excessive heat generated during mixing could denature the protein and gelatinize the starch, resulting in sticky dough. High dough temperature can also increase enzyme activity and deteriorate noodle quality. It is recommended that the water temperature be adjusted to achieve a final dough temperature of $25-30{ }^{\circ} \mathrm{C}$ (Hou, 2011).

\section{Dough development: lipid, protein and starch interactions}

Unlike bread making, dough development is not fully achieved while preparing dough for noodles. In noodle dough, proteins do not pull away from starch granules during mixing. The micro structure resembles that of compacted flour, which is due to the low moisture content of noodle dough (Moss, 1987). During noodle dough mixing, protein absorbs water and forms a limited gluten network, which glues other wheat flour components together, resulting in crumbly dough. Presence of protein-carbohydrate complexes in gluten (McMaster, 1983), binding of lipids to gluten proteins during dough mixing (Bekes, et al., 1983) and implication of both carbohydrate and lipid complex formation with glutenin proteins (Zawistowska, 1985) all directly or indirectly support the possible roles of starch granular proteins and lipids in starch-gluten interactions. Within a dough system, starch exists primarily in granular form, while protein is developed into a continuous threedimensional network. 
Scanning electron microscope studies would indicate that there is some disaggregation and mixing of protein component, largely responsible for dough development, but that is generally incomplete with some vestiges of intact cell components remaining (Moss, 1987). The viscous flow aspect of dough is known to be due to the monomeric gliadin component, whereas the polymeric glutenin gives the elasticity. Gluten is the important gas retaining protein. Concerning the importance of gliadin and glutenin subunits, both aggregate and individual (Kruger, 1996).

Excessively elastic gluten tends to produce a tough dough sheet, which shrinks back during the sheeting process, making it difficult to reduce the thickness and extend the length of the dough sheet, and making noodle strands nonpliable. On the other hand, surface peeling and tearing of the sheet could occur during sheeting through multiple rolls when the rate of gluten development is too slow or the developed gluten network is too small or weak to provide complete encapsulation of flour components. Protein component also determines the firmness of noodle (Ohio, 1985).

\section{Interaction of water on resting}

After completion of mixing, dough is allowed to rest to achieve proper distribution of water. Dough is rested in a receiving container while being stirred slowly (5-10 rpm). The stirring helps to dissipate heat inside the dough mass, prevent formation of large dough lumps, and feed dough crumbs into the sheeting rolls in a continuous process.

Resting produces smoother dough sheet as the protein mellows and becomes more extensible. Examination of dough microstructure shows rested dough has more uniform protein matrix and fewer air spaces (Moss, 1987). However, there is no change in the textural properties of adhesiveness, springiness and cohesiveness for noodles processed by superheated steam (Pronyk, 2008).Larger flour particle will take more time to incorporate water and thus having fairly fine particle size is beneficial. The most important thing affecting water absorption is the addition of alkali and salt.

Dough resting is also carried out in sheeting and size reduction as well by slowing down the speed of multilayer conveyor belt which is aided by temperature controlled and relative humidity controlled cabinet. Passing the dough sheets through a series of rolls with reduced roller gaps, gluten is further developed and aligned to the sheeting direction with further encapsulation of starch granules. The microstructure during the compression stage indicates that adjacent endosperm particles become fused together so that the protein matrix within one endosperm particle becomes continuous with that of adjacent particles. However, only a few sub aleurone protein masses show orientation in noodle dough and the fusion of the endosperm particle is not complete even at the end of the compression stage. The reduction stage which follows further develops the gluten. Uniform protein matrix is obtained at this stage (Moss, 1987).

The development and alignment of the gluten in the dough sheet allows noodle strands to be slit from the dough sheet without breakage or loss of shape during drying, frying and cooking process. Gluten protein content is negatively correlated with cooking loss, and positively with noodle tensile strength and firmness (Hou, 2013). The stage of dough resting helps moisture distribute more evenly. This also enhances disulfide bond formation and forms bond between gluten and lipid. Whether a dough sheet is allowed to rest or not has a significant impact on the degree of starch gelatinization during steaming. According to (Wu, 1998) well-rested dough has a higher degree of starch gelatinization than unrested dough, as examined by differential scanning calorimetric. The lack of evenly distributed water may prevent starch from being fully gelatinized during steaming. Meanwhile, the unrelaxed gluten may suppress starch swelling.

\section{Starch gelatinization and protein denaturation on steaming}

Noodles are subjected to steam to partially gelatinize and swell the starch which is needed for fast rehydration rate of the finished product before serving. Starch does not begin to gelatinize until it reaches $84^{\circ} \mathrm{C}$ even when the moisture is more than 70\% (Wu et al., 1998). The starch gelatinization temperature of noodles is therefore even higher than $84^{\circ} \mathrm{C}$. Generally, saturated steam is used for steaming the noodles. Drop in temperature results in condensation of steam. To overcome this defect superheated steam can also be used. Superheated steam is the steam with additional sensible heat to raise its temperature above corresponding saturation temperature at given pressure. When processing with superheated steam, noodles dry rapidly and become rapidly cooked. There is also much more gelatinization of starch when using superheated steam than saturated steam (Pronyk, 2008).Steaming denatures the protein and helps to fix the noodle waves. The protein denaturation process usually occurs prior to starch gelatinization because of relatively low moisture in noodles ( $40 \%$ moisture).

\section{Moisture loss during frying}

Frying of instant noodles is done at $140-160^{\circ} \mathrm{C}$ hot oil for 1-2 minutes. During the process, water vaporizes quickly form the surface of the noodle. Dehydration of outer surface of noodle drags water to migrate from the interior to the surface resulting porous spongy structure. These holes serve as channels for water to get in upon rehydration in hot water. Eventually, some of the water in noodles is replaced by oil. 
Because the surfaces of fried noodle strands absorb oil during frying, they can easily be separated in hot water. It usually takes 3-4 minutes to cook or soak fried instant noodles in hot water before consumption. The moisture content of the finished noodle products is in the range of $3-7 \%$. The main purpose of frying instant noodle is to remove excess water from the noodles, which causes weight loss accounts for 30 $-32 \%$ of the noodles.

\section{Thermal oxidation of lipid}

Series of complex reactions such as oxidation, hydrolysis, isomerization and polymerization take place during the deep-fat frying that influence quality attributes of the final product such as flavor, texture, shelf life and nutrient composition (Zhang, 2012). Saturated fat such as palm oil, beef tallow, vanaspati ghee etc. are used for deep frying of instant noodles in the industry. The reactions in deep fat- frying depends upon factors such as replenishment of fresh oil, frying conditions, original quality of frying oil, food materials, type of fryer, antioxidants, and oxygen concentration. High frying temperature, the number of frying, the contents of free fatty acids, polyvalent metals, and unsaturated fatty acids of oil decrease the oxidative stability and flavor quality of oil. The thermal oxidation rate is faster than the autoxidation. The mechanism of thermal oxidation involves the initiation, propagation, and termination of the reaction as shown in Figure 2.

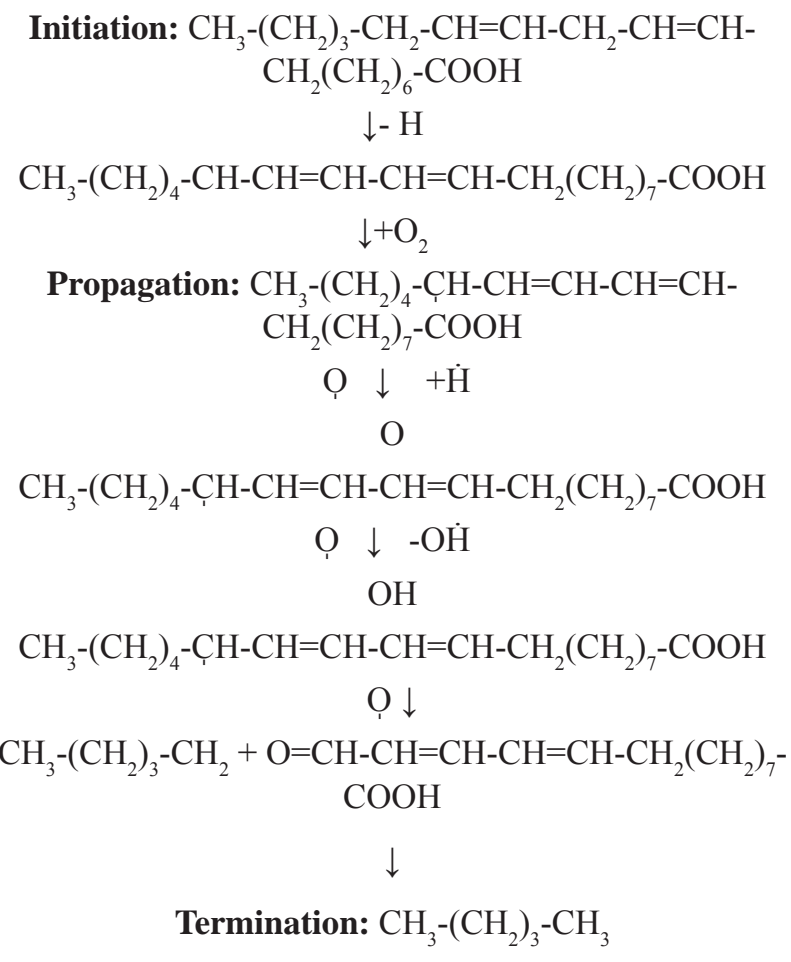

Figure 2. Thermal oxidation of oil (Min, 2007)
Water, steam, and oxygen initiate the chemical reactions in the frying oil and food. Water, a weak nucleophile, attacks the ester linkage of triacylglycerols and produces di and monoacylglycerols, glycerol, and free fatty acids. Free fatty acids contents in frying oil increase with the number of fryings (Chung, et al., 2004). Stevenson and others (1984) suggested that the maximum free fatty acid content for frying oil is $0.05 \%$ to $0.08 \%$. Antioxidant decreases the frying oil oxidation, but the effectiveness of antioxidant decreases with high frying temperature (Min, 2007). Antioxidants, Tertiary Butyl Hydroxy Quinone (TBHQ) is mostly used for palm oil and delta Tocopherol for beef tallow. It is well known that TBHQ shows greater stability than Butylated Hydroxy Quinone (BHQ) (Rho, 1986).

Decomposition of ester linkage takes place when water and heat are concomitant to each other (Houhoula, 2003). Thermal hydrolysis takes place mainly within the oil phase rather than water-oil interface (Lascaray, 1949). Hydrolysis is more preferable in oil with short and unsaturated fatty acids than oil with long and saturated fatty acids because short and unsaturated fatty acids are more soluble in water than long and saturated fatty acids. Water from foods is easily accessible to short-chain fats and oils for hydrolysis (Nawar, 1969). Water hydrolyzes the oil faster than steam (Pokorny, 1981). Frequent replacement of frying oil with fresh oil slows down the hydrolysis of frying oil (Romero, 1998) while polymer compounds increases with number of frying as illustrated in Figure 3. Di- and monoacylglycerols, glycerol, and free fatty acids accelerate the further hydrolysis reaction of oil (Frega, 1999). Glycerol evaporates at $150^{\circ} \mathrm{C}$ and the remaining glycerol in oil promotes the production of free fatty acids by hydrolysis (Naz, et al., 2005). Interestingly, Peroxide value (PV) of frying oil also increases with increasing frying time and temperature $\left(>180^{\circ} \mathrm{C}\right)$ although at low temperature, $\mathrm{PV}$ decreases with increasing time of frying oil Figure 4. Radical oxygen requires radical oil for the oxidation of oil. The hydrogen with the weakest bond on the carbon of oil will be removed first to become radical. The various strengths of hydrogen carbon bond of fatty acids explain the differences of oxidation rates of stearic, oleic, linoleic, and linoleic acids during thermal oxidation or autoxidation. The polyvalent metals as $\mathrm{Fe} 3+$ and $\mathrm{Cu} 2+$ remove hydrogen protons from oil to form alkyl radicals by oxidation-reduction mechanism of metals even at low temperatures. The site of radical formation in saturated fatty acids is different from those of unsaturated oleic or linoleic acids. The alkyl radical of saturated fatty acids is formed at $\alpha$ position of the carboxyl group having electron-withdrawing property. The high interfacial tension in the frying system breaks steam bubbles and forms a steam blanket over the oil surface. The steam blanket reduces the contact between the oil and oxygen, and lowers the oil oxidation (Blumenthal 1991). Addition of sesame oil can also improve thermo oxidative stability of the frying oil (Chung, et al., 2004). 
Shrestha et al.,: J. Food Sci. Technol. Nepal, Vol. 9 (1-10), 2016

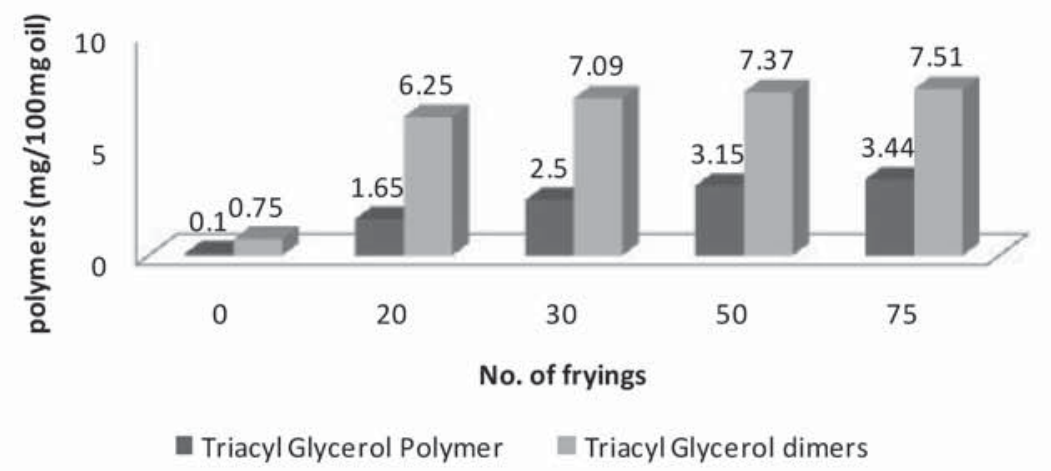

Figure 3. Formation of Triacyl Glycerol Polymers during frying of potatoes (Cuesta, 1993)
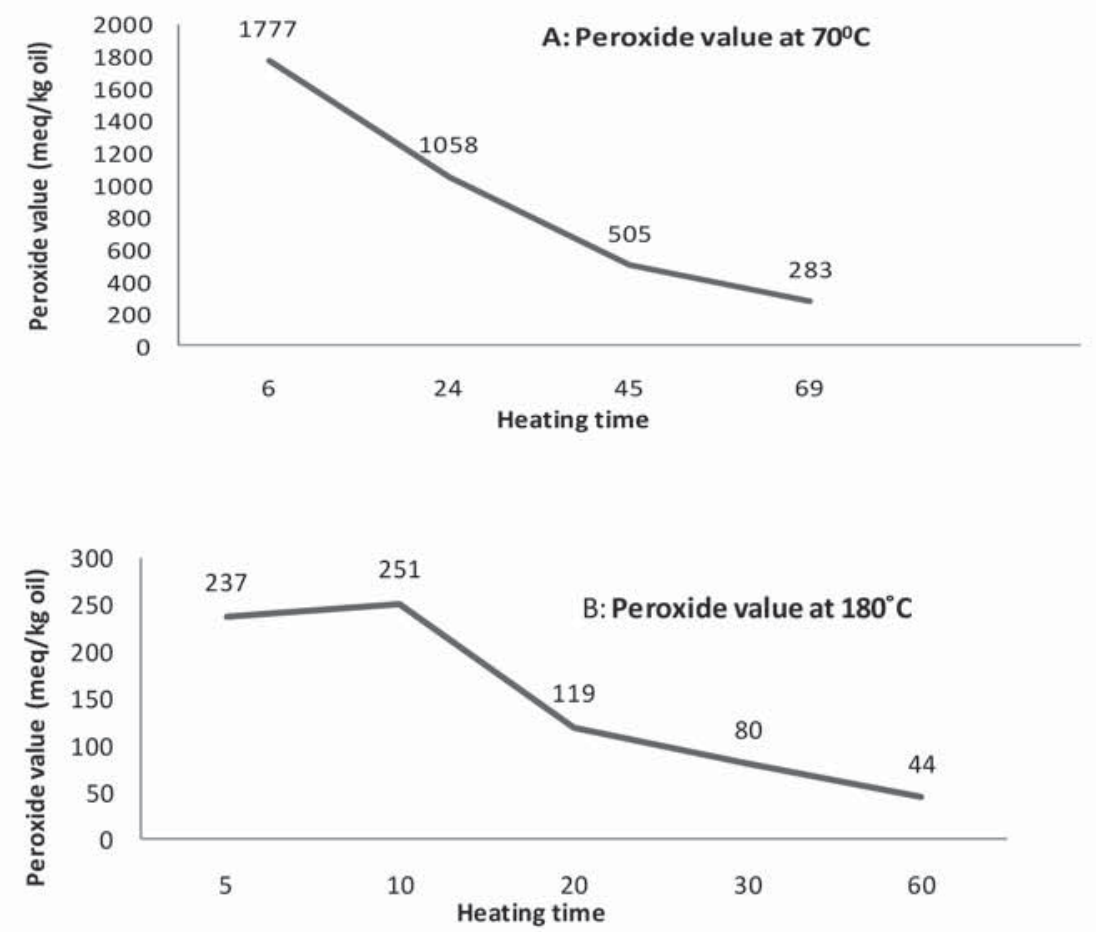

C: Peroxide value at $250^{\circ} \mathrm{C}$

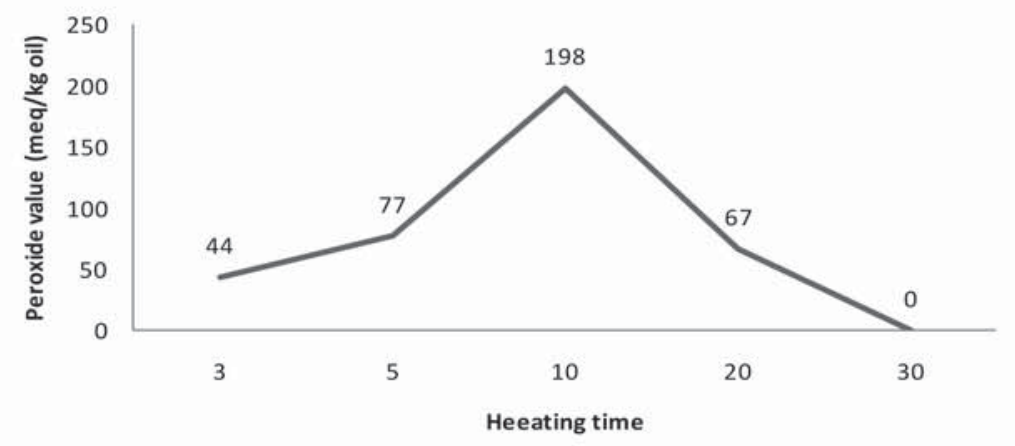

Figure 4: POV of frying oil at different time and temperatures A, B, C (Nawar, 1984) 


\section{Rancidity}

Rancidity of oil and fat is attributed to autoxidation. These volatile aldehyde compounds have been found to have certain potential threat to health of consumer (KamalEldin, 1996, Seppanen, 2002) especially the genotoxic and cytotoxic properties of unsaturated aldehydes (Guillén, 2008). The genotoxic and cytotoxic olefine aldehydecontained compounds produced have been reported to be absorbed by the fried material (Seppanen, 2004, Seppanen, 2006). Volatile compounds such as acids, hydrocarbons, alcohols, aldehydes, ketones, esters, lactones and aromatic compounds were detected in separate studies carried out by (Kawada, 1967; Yasuda, 1968; Chang, 1978; Thompson, 1978; May, 1983.) Rancidity of frying oil and fried noodles occurs manly due to poor storage technique or long storage time.

\section{Formation of polymers}

The major decomposition products of frying oil are nonvolatile polar compounds and triacylglycerol dimers and polymers. Dimers and polymers are large molecules with a molecular weight range of 692 to 1600 Daltons and formed by a combination of -C-C-, -C-O-C-, and -C-OO-C- bonds (Stevenson, et. al., 1984; Kim, et. al., 1999). Polymerization in deep-fat frying is radical reactions. Allyl radicals are formed preferably at methylene carbons $\alpha$ to the double bonds. Dimers are formed from the reactions of allyl radicals by C-C linkage. Polymers formed in deep-fat frying are rich in oxygen (Tseng et al., 1996). Polymers accelerate further degradation of the oil, increase the oil viscosity, reduce the heat transfer, produce foam during deep-fat frying, and develop undesirable color in the food. Polymers also cause the high oil absorption to foods. The major reaction products formed during deep-fat frying are, oxidized decomposition compounds, hydrolysis products, oxidized TAG polymers, cyclic fatty acid monomers, trans isomers, TAG polymerized products, sterol derivatives, antioxidant alterations, heterocyclic compounds and acrylamide (Zhang, 2012).

\section{Frying: Integrated relationship between of lipid, pro-} tein, starch and water

Upon addition of the food to the hot oil, the surface temperature of the food rises rapidly. The water at the surface immediately starts boiling and surrounding oil is cooled down, compensated by convection. As the boiling furthers, the convection is further intensified by the turbulent water vapor. Due to the evaporation, surface drying will occur. The evaporation will also lead to shrinkage and development of surface porosity and roughness (Mellema, 2003). Foods fried at the optimum temperature and time have golden brown color, are properly cooked, and crispy, and have optimal oil absorption. Similarly, over fried foods at higher temperature and longer frying time than the optimum frying have darkened and hardened surfaces and a greasy texture due to the excessive oil absorption (Blumenthal, 1991). Fat content of instant fried noodles tends to increase as flour protein content decreases while fat absorption of instant noodles tends to increase as starch amylose content decreases (Park and Baik, 2002).The hydrolysis, oxidation, and polymerization of oil are common chemical reactions in frying oil and produce volatile or nonvolatile compounds. The nonvolatile compounds in the oil change the physical and chemical properties of oil and fried foods.

\section{Acrylamide formation}

Acrylamide refers to 2-propenamide $\left(\mathrm{C}_{3} \mathrm{H}_{5} \mathrm{NO}\right)$ which has also been known as, ethylene carboxamide, acrylic acid amide, vinyl amide or propenoic acid amide. Acrylamide appears as a white crystalline solid and the solubilities (expressed in units of $\mathrm{g} / 100 \mathrm{~mL}$ of solvent at $30^{\circ} \mathrm{C}$ are: water 215.5, methanol 155, ethanol 86.2, acetone 63.1, ethyl acetate 12.6, chloroform 2.66 , benzene 0.346 , and heptanes 0.0068 . The melting point is $84.5^{\circ} \mathrm{C}$ and its boiling point is $125^{\circ} \mathrm{C}$ at $25 \mathrm{mmHg}$ and $192.6^{\circ} \mathrm{C}$ at atmospheric pressure (Budavari, et al., 1989). Acrylamide is formed when food, particularly those rich in carbohydrate are cooked at above $120^{\circ} \mathrm{C}$ (WHO/FAO, 2002) especially those prepared by grilling, roasting, baking, frying and deep-frying (Risk Assessment Section, 2003). Acrylamide in the instant noodles ranged from 11.6 to $77.4 \mu \mathrm{g} / \mathrm{kg}$ (Kawila, 2011). In Noodles, amino compound and aldoses when mediated by high processing temperature may react to give melanoidin, end product of Maillard reaction. The Maillard reaction is exceptionally widespread. It occurs virtually ubiquitously in foodstuffs, particularly during processing at elevated temperatures (Nursten, 2005). Carbonyl compounds produced in the lipid oxidation pathway competes with carbohydrate-derived carbonyls for amino compounds to produce carbonyl-amine reaction products (Zamora, 2011)

Researchers have found that acrylamide possesses neurotoxicity, genetic toxicity and carcinogenicity (Friedman, 2003; Hagmar, Wirfält, Paulsson, \& Törnqvist, 2005; Jafari, 2011; Keramat, 2011). Acrylamide is mainly produced by the reaction between some amino acids and reducing sugar on high temperature or during the pathway of maillard reaction (Stadler et al., 2002 ; Jafari, 2011; Keramat, 2011). Amino acid combined with a dicarbonyl compound and then subjected to intramolecular rearrangement of ion and strecker degradation to form an acrolein, a hydrogen nitride and other compounds or strecker aldehyde (Donald, et al., 2002). Acrylamide is formed from the combination of acrylic acid and hydrogen nitride or ammonium originated from nitrogen containing compounds. 
Except the reducing sugar as source of carbonyl compound, some of the lipid oxidation products which occur during deep-fat frying, promote or participate in the formation of acrylamide. The more susceptible to oxidation of the frying oil, the more Acrylamide is formed (Capuano, et al., 2010).

Acrylamide concentration is much higher when palmolein is used as frying oil due to its high content of diglycerides (6 to $8 \%$ ). This might be attributed to another formation pathway of the aminoacid precursor of acrolein (Klostermann, 2002) or formed from glycerol when the frying temperature is higher than the smoke point of frying oil (Claeys, 2005). Therefore, control of the type of frying oil, frying temperature and time are effective to control the producing of acrylamide. Palm oil contains about $45 \%$ saturated fat and is more stable than palmoleinand other vegetable oils (Fennema, 1985). Among myriad of choices of atioxidants, such as TBHQ, tocopherols (vitamin E), BHA, or BHT or their mixtures TBHQ is reported to have the best efficiency to prolong the shelf life of fried noodles.

It was found that Maillard reactions generating compounds responsible for smashing taste, aroma and color of foods are coupled with formation of acrylamide from asparagine and reducing sugars (Zhang, 2009). Currently it is clearly known that this compound is also one of triacylglycerols thermal degradation products that is formed during food processing at very high temperature. The intensity of acrylamide formation in foods containing asparagine and reducing sugars depends on initial concentrations of these precursors and their ratio as well as on temperature and duration of thermal treatment, water activity and $\mathrm{pH}$ (Shibamoto, 2005; Claus, et al., 2008; Hedegaard, 2008).

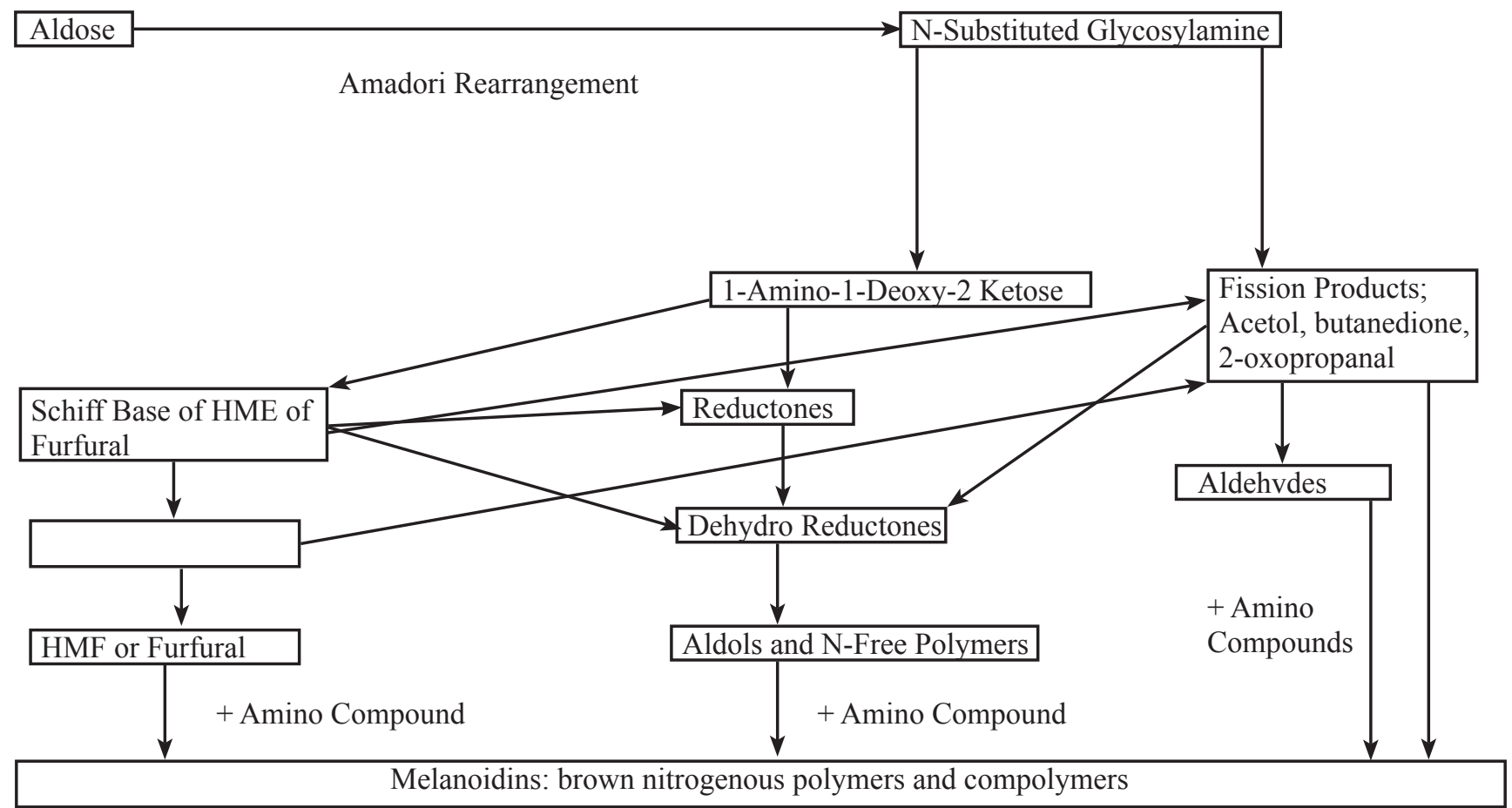

Figure 5. Reaction pathway of non enzymatic browning in food. Adopted from Nursten, 2005.

Traditionally, High Performance Liquid Chromatography (HPLC) and Gas Chromatography (GC) were only used to measure acrylamide quantitatively. Novel analytical technique uses Capillary Ecectrophoresis (CE), Enzyme Linked Immunological Assay (ELISA) and Electrochemical biosensors. Among these methods, use of biosensors are and ELISA are the most promising one as they allow fast screening of numerous samples without usage of sophisticated apparatus. HPLC, GC and CE are time consuming sample preparation and use expensive equipment (Oracz, et al., 2011).

\section{Noodle color and Noodle darkening}

During frying, noodle develops characteristic golden or yellow color. The degree of yellowness in noodles is not only dependent on the alkali used in formulation alone but also on the wheat variety and yellow pigment of the flour (Kruger, 1996). Flavones are colorless at acidic $\mathrm{pH}$ and present in great amount in germ and bran. Raw noodle become darker and yellow with time after manufacture as attributed by presence of bran specks ad enzymatic browning by polyphenol oxidases (Moss, 1985). Polyphenol oxidases, 
tyrosinase, phenol oxidase, phenolase) exist in multiple forms and are concentrated in the bran (Kruger, 1988). The enzymes oxidizes phenols to quinones that turns into dark colored pigments (melanoidins) by self-polymerization and resonance stabilization of aromatic ring structure so formed or by interaction of amino group with proteins. Microscopic examination of noodle shows that most darkening is in the form of spots developing around a nucleus of nonendosperm material (Moss, 1985).

\section{Microscopic imagining of Noodles}

Most of the increased understanding of the mechanism of molecular interactions has been brought about by improved imaging techniques. Recently, confocal laser scanning microscopy (CLSM) could be regarded as a potential tool for understanding the effect of processing and the influence on bio- macromolecules. A microstructural change in instant noodles during production has been studied using CLSM to monitor microstructural differences (Dürrenberger, et al., 2001; Lalana, 2001; Sangpring, et al., 2015).

\section{Conclusion and recommendations}

Beyond art of just producing noodles out of wheat flour, if we become able to understand physiochemical reaction mechanisms along with different stages of processing, it beneficial not only from economic prospective of industry but also from health prospective of consumer. Acrylamide possesses neurotoxicity, genetic toxicity and carcinogenicity (Friedman, 2003). Consumers are concerned of negative impacts of Maillard Reaction Products (MRPs) on health and their desirability of reducing fat, salt and gluten content of deep fried products obliges food industries to study Several physicochemical changes that take place during processing (gluten network, gelatinization, Maillard reactions, glass transitions). This will lead to discovery beneficial organoleptic properties and color of the crust. Therefore, industries should find intelligent way of utilizing the resources at its optimum. For example: optimum temperature of frying oil, heat supplied, mixing time, steaming time and temperature etc. This will help to save surfeit inputs like steam, heat, frying oil etc. and meet the quality of the product at its highest degree of safety. Thus produced Asian Noodles should have protein (7-10\%), fat $(16-22 \%)$ and moisture $(<3 \%)$ (Hou, 2011)

However, when looked with meticulous scrutiny, there are myriad of enigmas. Reaction pathway of acrylamide formation is still nebulous and much work to be done on formation of amadori compounds and different polymers formed during frying and its precise detection. Researches can be done to overcome these problems and to have insight knowledge to the perfection.

\section{References}

Bekes F., Zawistowska U. and Bushuk W. (1983). Protein-lipid complexes in the gliadin fraction [Wheat flour, bread-making properties]. Cereal chemistry.

Blumenthal M. M. (1991). A new look at the chemistry and physics of deep-fat frying. Food technology (USA).

Budavari S., O’Neil M. J., Smith A. and Heckelman P. E. (1989). The merck index (Vol. 11): Merck Rahway, NJ.

CAC (2016). Standard for Durum Wheat Semolina and Durum Wheat Flour (CODEX STAN 178-1991). In: Codex Alimentarious: http://www.codexalimentarius.org/standards/list-of-standards/ en/? provide $=$ standards\& orderField $=$ fullReference \& $s o r t=a s c \&$ num $1=$ CODEX

Chang S. P. (1978). Chemical-reactions involved in deep-fat frying of foods. Journal of the American Oil Chemists' Society 55: 718727.

Choe E. and Min D. (2007). Chemistry of deep fat frying oils. J. of Food Science, 72(5): R77-R86.

Chung J., Lee J. and Choe E. (2004). Oxidative stability of soybean and sesame oil mixture during frying of flour dough. Journal of Food Science, 69(7): 574-578.

Claeys W. V. (2005). Quantifying the formation of carcinogens during food processing: acrylamide. Trends in Food Science \& Technology 16: 181-193.

Claus A., Carle R. and Schieber A. (2008). Acrylamide in cereal products: A review. Journal of cereal Science, 47(2):118-133.

Cuesta C., Sánchez-Muniz F., Garrido-Polonio C., López-Varela S. and Arroyo R. (1993). Thermoxidative and hydrolytic changes in sunflower oil used in fryings with a fast turnover of fresh oil. Journal of the American Oil Chemists Society, 70(11): 1069-1073.

Donald S., Bronislrnv L. and Andrew T. (2002). ACrylarnide is formed in the maillard reaction. Nature, 419: 448-449.

Dürrenberger, M. B., Handschin, S., Conde-Petit, B., \& Escher, F. (2001). Visualization of food structure by confocal laser scanning microscopy (CLSM). LWT-Food Science and Technology, 34(1):11-17.

Edoardo Capuanoa T. O. (2010). Lipid oxidation promotes acrylamide formation in fat rich model system. Food Research International, 1021-1026.

Fennema R. O. (1985). Food Chemistry, 2nd ed. New York, USA: Marcel Dekker.

Frega N. M. M. (1999). Effects of free fatty acids on oxidative stability of vegetable oil. American Oil Chem. Soc., 76:325-9.

Friedman M. (2003). Chemistry, biochemistry and safety of acrylamide. A review. Journal of Agricultural and Food Chemistry, 4504-4526.

Fu B. X. (2008). Asian noodles: History, classification, raw materials, and processing. Food Research International, 888-902.

Fu B., Assefaw E., Sarkar A. and Carson G. (2006). Evaluation of durum wheat fine flour for alkaline noodle processing. Cereal foods world, 51(4): 178-183. 
Gary G. and Hou R. S. (2013). Relationship Between Physicochemical Properties of Wheat Flour, Wheat Protein Composition, and Textural Properties of Cooked Chinese White Salted Noodles. Cereal Chemistry, 419-429.

Guillén M. G. (2008). Toxic Oxygenated, unsaturated aldehyde and their study in foods: a review. Critical Reviews in Food Science and Nutrition 48: 119-136.

Hagmar L., Wirfält E., Paulsson B. and Törnqvist M. (2005). Differences in hemoglobin adduct levels of acrylamide in the general population with respect to dietary intake, smoking habits and gender. Mutation Research/Genetic Toxicology and Environmental Mutagenesis, 580(1): 157-165.

Hedegaard R.V. and F. H. (2008). Kinetics of formation of acrylamide and Schiff base intermediates from asparagine and glucose. Food Chemistry, 917-925.

Hou, G. G. (2011). Asian noodles: Science, technology, and processing: John Wiley \& Sons.

Houhoula D. O. (2003). Effect of procesing time and temperature on the accumulation of polar compounds in cottonseed oil during deep fat frying. Journal of the science of Food and Agriculture, 314-319.

Jafari J. K. (2011). Acrylamide in baking products: a review article. Food Bioprocess Technology, 530-543.

Kamal-Eldin A. A. (1996). Aldehyde acids in frying oil: formation, toxicological significance and analysis. Grasas y Aceites 47: 342348 .

Karim R. (1990). Texural studies on chinese wet noodles (Hokkienstyle noodles. Universiti pertanian Malaysia.

Kawada T. K. (1967). Chemical reactions involved in the deep fat frying of foods. II. Identification of acidic volatile decom-position products of corn oil. . Journal of the American Oil Chemists Society 44: 131-135.

Kawila N. (2011). Studies of niacin and acrylamide during processing of instant Asian noodles. Melbourne, Australia.

Keramat A. L. (2011). Acrylamide in foods: chemistry and analysis. A review. Food Bioprocess Technology, 340-363.

Kim, I.-H., Kim, C.-J., \& Kim, D.-H. (1999). Physicochemical properties of methyl linoleate oxidized at various temperatures. Korean Journal of Food Science and Technology, 31(3), 600-605.

Klostermann C. G. (2002). Analsis of Acrylamide and mechanisms of its formation in deep fird products. European Journal of Food Science and Technoogy, 762-771.

Kruger J. (1996). Asian Noodles. In R. B. James E. Kruger, Pasta and Noodle Technology.

Kruger J., Reed G. and Pomeranz Y. (1988). Enzymes and color. Wheat: chemistry and technology. Volume I. (Ed. 3): 441-500.

Lalana Chewangkul, O. N. (2001). Microstructural Changes in Instant Noodles During Production via Triple Staining and Confocal Laser Scanning Microscopy andScanning Electron Microscopy.

Lascaray L. (1949). Mechanism of fat splitting. Industrial \& Engineering Chemistry, 41(4): 786-790.
Lu, Q., Guo, S., \& Zhang, S. (2009). Effects of flour free lipids on textural and cooking qualities of Chinese noodles. Food Research International, 42(2): 226-230.

Maher G. (1983). Alkali gelatinization of starches. Starke, pp. $35: 226$ - 234.

May W. P. ( 1983). Chemical reactions involved in the deep- fat frying of foods. IX. Identification of the volatile decomposition products of triolein. Journal of the American Oil Chemists' Society 60: 990-995.

McMaster G. J. (1983). Protein - carbohydrate complexes in gluten: fractionfractionation and proximate composition (functionality of gluten in bread doughs). Cereal Sci., 77-85.

Mellema M. (2003). Mechanism and reduction of fat uptake in deep fat fried foods. Trends in Food Science and Technology, 364-373.

migration, and texture of rice noodle. $L W T$ - Food Science and Technology $64: 1107-1113$.

Moss H. (1985). Chinese Noodle Production: Wheat Flour Quality and Processing Factors. Australian Wheat Board, Melbourne.

Moss H., Miskelly D. and Moss R. (1986). The effect of alkaline conditions on the properties of wheat flour dough and Cantonesestyle noodles. Journal of cereal Science, 4(3): 261-268.

Moss R. G. (1987). The Influence of ingredients and processing variables on the quality and microstructur of Hokkien, Cantonese and instant noodles. Food Microstructure, (pp. 63 - 74).

Nawar W. W. (1969). Thermal degradation of lipids. Journal of agricultural and food chemistry, 17(1): 18-21.

Nawar W. W. (1984). Chemical changes in lipids produced by thermal processing. Journal of chemical education, 61(4): 299.

Naz S., Siddiqi R., Sheikh H. and Sayeed S. A. (2005). Deterioration of olive, corn and soybean oils due to air, light, heat and deepfrying. Food Research International, 38(2): 127-134.

Noda T., Tohnooka T., Taya S. and Suda I. (2001). Relationship between physicochemical properties of starches and white salted noodle quality in Japanese wheat flours. Cereal chemistry, 78(4): 395-399.

Nursten H. (2005). The Maillard Reaction Chemistry, Biochemistry and Implications. The University of Reading, Reading, UK: Royal Society of Chemistry.

Ohio N. S. (1985). Influence of Flour Protein, extraction rate, particle size and starch damage on the quality charactristics of dry noodles. Food Microstructure, pp. 441- 446.

Oracz J., Nebesny E. and Żyżelewicz D. (2011). New trends in quantification of acrylamide in food products. Talanta, 86: 23-34.

Park C. S. and Baik B.-K. (2002). Flour characteristics related to optimum water absorption of noodle dough for making white salted noodles. Cereal chemistry, 79(6): 867-873.

Pokorny J. (1981). Browning from lipid-protein interactions. Progress in food and nutrition science.

population with respect to dietary intake, smoking habits and gender. Mutation Reesearch: Genetic Toxicity and Environmental Mutagenesis, 157-165. 


\section{Shrestha et al.,: J. Food Sci. Technol. Nepal, Vol. 9 (1-10), 2016}

Pronyk C. C. (2008). effects of dough resting tme and saturated steam pre-treatment on the textural properties of superheated steam processed nstant Asian noodles. Canadian Biosystems engineering.

Rho K. S. (1986). Retardatio of rancidity in deep fried instant noodles (ramyon). JACOS, pp. 63: 251 - 256.

Risk Assessment Section. (2003). Acrylamide in Food. Food and Public Health Branch of the Food and Environmental Hygiene Department of the Government of the Hong Kong Special Administrative Region.

Rombouts I., Jansens K. J., Lagrain B., Delcour J. A. and Zhu K.X. (2014). The impact of salt and alkali on gluten polymerization and quality of fresh wheat noodles. Journal of cereal Science, 60(3):507-513.

Romero A., Cuesta C. and Sánchez-Muniz F. J. (1998). Effect of oil replenishment during deep-fat frying of frozen foods in sunflower oil and high-oleic acid sunflower oil. Journal of the American Oil Chemists' Society, 75(2): 161-167.

Ross A. S. (2005). Guidelines for the laboratory manuacture of asian wheat flour noodles. Cereal Foods World 50: 296-304.

Sangpring, Y., Fukuoka, M., \& Ratanasumawong, S. (2015). The effect of sodium chloride on microstructure, water migration, and texture of rice noodle. LWT-Food Science and Technology, 64(2):1107-1113.

Seppanen C. A. (2006). The effect of intermittent and continuous heating of soybean oil at frying temperature on the formation of 4-hydroxy- 2-trans-nonenal and other unsaturated hydroxyaldehydes. Journal of Ameerican Oil Chemists' Society 83: $121-127$.

Seppanen C. C. (2002). Formation of 4-hydroxynonenal, atoxic aldehyde in soybean oil at frying temperature. Journal of American Oil Chemists' Society 79: 1033-1038.

Seppanen C. C. (2004). Incorporation of toxic aldehyde 4-hydroxy2-trans-nonenal into food fried in thermally oxidized soybean oil. Journal of american Oil Chemists' Society 81: 1137-1141.

Shibamoto S. E. (2005). Correlation of Acrylamide Generation in Thermally Processed Model Systems of Asparagine and Glucose with Color Formation, Amounts of Pyrazines Formed, and Antioxidative Properties of Extracts. Journal of Agriculture and Food Chemistry, 4813-4819.

Stadler R. H., Blank I., Varga N., Robert F., Hau J., Guy P. A. and Riediker S. (2002). Food chemistry: acrylamide from Maillard reaction products. Nature, 419(6906): 449-450.

Stevenson, S., Vaisey-Genser, M., \& Eskin, N. (1984). Quality control in the use of deep frying oils. Journal of the American Oil Chemists Society, 61(6), 1102-1108.

Terada M. M. (1978). A component of wheat flour globulin polymerized at alkaline sides and depolymerized by reduction revesrsibility. In Agricultural and Biological Chemistry (pp. 42:1397-1402).

Thompson J. M. (1978). Chemical reactions involved in the deepfat frying of foods. VII. Identification of volatile decompo-sition products of trilinolein. Journal of the American Oil Chemists' Society 55: 897-901.
Tsai C. S. (2007). Biomacromolecules, introduction to structure function and informatics. New jersey: John Wiley \& Sons.

WHO/FAO (2002). Health Implications of Acrylamide in Food: Report of a joint FAO/WHO consultation. Geneva: WHO.

Wu T. P. (1998). Modern noodle based foods-product range and production methods. Pacific people and their foods, 37- 89.

Yasuda K. R. (1968). Chemical reactions involved in the deep fat frying of foods. IV. Identification of acidic volatile decomposition products of hydrogenated cottonseed oil. . Journal of the American Oil Chemists' Society 45: 625-628.

Zamora R. H. (2011). The maillard reaction and lipid oxidation. . Lipid Technology 23: 59-62.

Zawistowska U. B. (1985). Gluten proteins with high affinity to flour lipids. Cereal Chem, 62: 284-289.

Zhang Q., Saleh A. S., Chen J. and Shen Q. (2012). Chemical alterations taken place during deep-fat frying based on certain reaction products: a review. Chemistry and physics of lipids, 165(6): 662-681.

Zhang Y., Ren Y. and Zhang Y. (2009). New research developments on acrylamide: analytical chemistry, formation mechanism, and mitigation recipes. Chemical reviews, 109(9): 4375-4397. 